\title{
Monoallelic Gene Expression in Mice: Who? When? How? Why?
}

\author{
John Schimenti
}

The Jackson Laboratory, Bar Harbor, Maine 04609, USA

I cluster of three genes in the mouse $t$ complex that exhibit random monoallelic expression, representing a new example of somatic mosaicism. These findings are fascinating from several perspectives, raising questions that make for entertaining speculation by casual and dedicated observers of the epigenetics field. What is the biological reason for monoallelic expression? What is the mechanism? Is it just stochastic or is it a critical mode of transcriptional regulation? Do monoallelically-expressed genes occur primarily in clusters?

\section{Link to Methylation}

One key aspect of Sano et al.'s findings was the correlation between methylation status and the expression (or non-expression) of the alleles. In the cell types investigated by Southern blot analysis with the enzymes HpaII and MspI, approximately half the genomic DNA could be cleaved at certain HpaII sites, indicating that half the sites were methylated. However, it was not determined directly if the non-expressed allele was also the methylated allele, or vice versa. Nevertheless, this observation has potential significance with respect to mechanism. If the methylation state is what dictates which allele is active, then this would eliminate the possibility that monoallelic expression is a consequence of limiting amounts of cognate transcription factors. The other important issue to consider is the clustering of the three monallelicallyexpressed genes. Is this a coincidence, or do alleles on the same chromosome undergo silencing or activation in a coordinated way? If the latter is true, a chromatin-driven type of mechanism would again be implicated, as opposed to one invoking limiting quantities of transcription factors. This question of clustering could be tested if the expressed allele of all three of the genes discovered by Sano and colleagues were determined in individual cells.

E-MAIL jcsjax.org; FAX (207) 288-6082. Article and publication are at http://www.genome. org/cgi/doi/10.1101/gr.215601.

\section{How Does it Work?}

To further build on the speculation that the selection of alleles for expression is driven by a chromatin-driven mechanism, possibly methylation, a clear distinction can be drawn between monoallelic expression and classical imprinting. Once an imprinting pattern is laid down during development (assuming that methylation is a key component of imprinting), it is preserved by maintenance methylases (for review, see Bestor 2000). The experiments of Sano et al (2001) showed that newly established clones of bone marrow stromal cells were divided equally with respect to which allele they expressed. If the methylation status of a monoallelically expressed gene and transcription is causally linked, it would be possible that either the methylation pattern changes at every generation, or is randomly determined at each division. Thus, de novo methylation might be required at every cell division. If so, then maintenance methylation at the relevant loci might be overridden or suppressed.

The possibility that the expressed allele shifts at every cell division would be difficult to address experimentally, but it might yield key insights into the mechanism of the process. Some conclusions might be obtained through the use of transgenic mice. By putting a third copy of a monoallelicallyexpressed gene into the genome, it would be interesting to see if only one of the three copies is expressed, or if the transgene plus one of the endogenous alleles were expressed. Furthermore, if the transgene were rendered homozygous, would it be subject to monoallelic expression? This would give clues as to whether (1) the phenomenon is intrinsic to the genes themselves, (2) it is influenced by chromatin, (3) the quantities of cognate transcription factors are limiting or (4) a cosuppression-type process is at work. It would also be interesting to examine expression of these genes in mice heterozygous for a $t$ haplotype, which carries large inversions, or a deletion of the region. The patterns in these situations might yield clues as to whether physical alignment of homologous chromosomes is required (which might be disrupted by the inversion), or if the presence of a homolog is required for silencing.

\section{Ramifications of Monoallelic Expression}

An important implication for monoallelic expression is that it may play a role in haploinsufficiencies or deletion syndromes (also referred to as contiguous gene syndromes, or CGSs). It is conceivable that CGSs are not entirely a consequence of reduced levels of expression in all cells, but that as a result of to monoallelic expression some cells do not express deleted genes at all because the remaining copy has been silenced. Interestingly, my lab has found that chromosomal deletions that extend into the region of the $t$ complex containing the genes reported by Sano et al (2001) cause a strain-specific haplolethality, in which deletion-bearing embryos die of a common cause (Browning et al., in prep.). It will be interesting to determine if these genes are responsible. It is also worth considering a potential role of monoallelic expression in cancer. If tumor suppressor or metastasis genes are subject to monoallelic expression, then de novo somatic mutations in one allele might render a competitive growth advantage upon those daughter cells that happen to inactivate the remaining nonmutant allele. One then wonders if such genes have undergone evolutionary selection NOT to be subject to monoallelic expression.

\section{Monoallelic Expression and the $t$ Complex}

What implications does the discovery of monoallelically expressed genes have for the mouse $t$ complex? To briefly review, the $t$ complex is a $\sim 20-30 \mathrm{Mb}$ region on proximal mouse 17 that is thus recognized because there are mutant versions of this region in the wild (termed " $t$ haplotypes"). These $t$ haplotypes carry mutations affecting spermatogenesis (causing male segregation distortion and infertility), and embryogenesis (different $t$ haplotypes around the world have a variety of different recessive lethal mutations). The several genes responsible for these phenotypes are genetically locked together by four large inversions. As one of the longest studied 
genetic systems in mice, it retains an air of mystery, in some part due to its stubborn resistance to yield its secrets to investigators such as myself. Does the monoallelic expression observed by Sano et al. have anything to do with phenotypes associated with $t$ haplotypes, and is the $t$ complex especially rich in monoallelically expressed genes? The classical $t$ haplotype lethal mutations are recessive, and show no phenotype in the heterozygous state; thus, it is unlikely that the monoallelically expressed genes are involved in these phenotypes. It would have to be shown that the $t$ haplotypes differ in some way from the patterns of monoallelic expression observed in wild-type chromosomes reported by Sano et al. It is worth considering, however, that at least one of the genes involved in $t$ haplotype segregation distortion behaves as a null, and exerts effects in the heterozygous state (Lyon 1992; Planchart et al. 2000). If this gene were to undergo random monoallelic expression, then mice heterozygous for a $t$ haplotype would express only one-fourth normal levels, possibly mimicking a severe hypomorphic situation. As for whether the $t$ complex may be especially rich in monoallelically expressed genes, this awaits further study. However, as Minoru Ko's previous work demonstrated, a disproportionately large majority of cDNA clones isolated from early extraembryonic tissues are located within the $t$ complex (Ko et al. 1998). Thus, in conjunction with the large list of known recessive mutations, it is possible that the $t$ complex is enriched for developmentally important genes, and that this class of genes is particularly susceptible to monoallelic expression. Nevertheless, it is clear that this phenomenon is not specific to the $t$ complex, given the monoallelic expression of X-linked genes in females and the confirmation that at least one other autosomal gene is monoallelically expressed, not as a consequence of allelic exclusion associated with genomic rearrangements (Hollander et al. 1998; Rhoades et al. 2000).

\section{Is There a Function for Monoallelic Expression?}

Sano et al. end their paper with the key question that all readers will have: What is the reason for monoallelic expression of the sort seen in these genes? They offer some potential explanations: (1) That it is a way to decrease expression of particular genes in development; (2) it is a bystander effect from nearby imprinted genes; or (3) it is a stochastic consequence of genes expressed at extremely low levels. In first case, one would have to reconcile this with the fact that the genes in the cluster appear to be unrelated, yet they might be coordinately subjected to monoallelic expression. I would like to offer another possibility, although it is probably unlikely: It is a method to counteract existence of semidominant mutations or incompatible allelic combinations in actively dividing cell types. If a deleterious dominant/ semidominant allele existed in a cell, the process of monoallelic expression would allow half the cells to function normally, especially if the pattern of alternation were totally random.

In summary, this interesting study generates more questions than answers. Somehow, the subject of epigenetics has the ability to elicit fascination, curiosity, and stimulating speculation from all who are exposed to it, regardless of whether or not it is a topic of their own research. The next chapter in this story will be eagerly awaited, not only for the purpose of understanding the biological implications, but also because of its high intrinsic interest. I am an avid sci-fi fan, but in this case reality is more fascinating than fiction.

\section{REFERENCES}

Bestor, T.H. 2000. Hum. Mol. Genet. 9: 2395-2402. Hollander, G. A., Zuklys, S., Morel, C., Mizoguchi, E., Mobisson, K., Simpson, S., Terhorst, C., Wishart, W., Golan, D.E., Bhan, A.K., et al. 1998. Science 279: 2118-2121.

Ko, M. S., Threat, T.A., Wang, X., Horton, J.H., Cui, Y., Pryor, E., Paris, J., Wells-Smith, J., Kitchen, J.R., Rowe, L.B., et al. 1998. Hum. Mol. Genet. 7: 1967-1978.

Lyon, M. 1992. Genet. Res. Camb. 59: 27-33.

Planchart, A., You, Y., and Schimenti, J.C. 2000. Genetics 155: 803-812.

Rhoades, K.L., Singh, N., Simon, I., Glidden, B., Cedar, H., and Chess, A. 2000. Curr. Biol. 10: 789-792.

Sano, Y., Shimada, T., Nakashima, H., Nicholson, R. H., Eliason, J. F., Kocarek, T. A. and Ko, M. 2001. Genome Res. 1833-1841. 


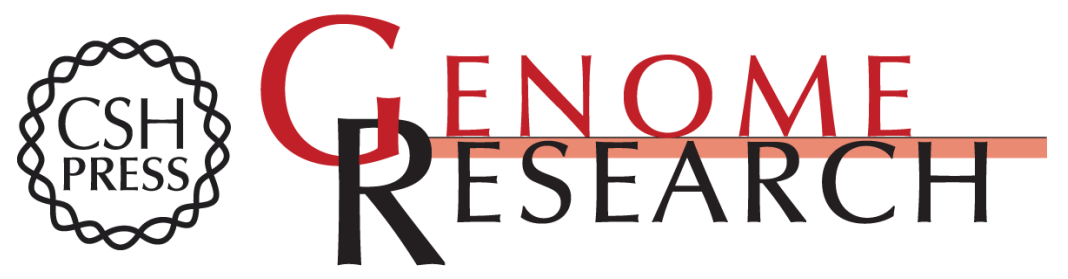

\section{Monoallelic Gene Expression in Mice: Who? When? How? Why?}

John Schimenti

Genome Res. 2001 11: 1799-1800

Access the most recent version at doi:10.1101/gr.215601

References This article cites 6 articles, 2 of which can be accessed free at:

http://genome.cshlp.org/content/11/11/1799.full.html\#ref-list-1

License

Email Alerting Receive free email alerts when new articles cite this article - sign up in the box at the Service top right corner of the article or click here.

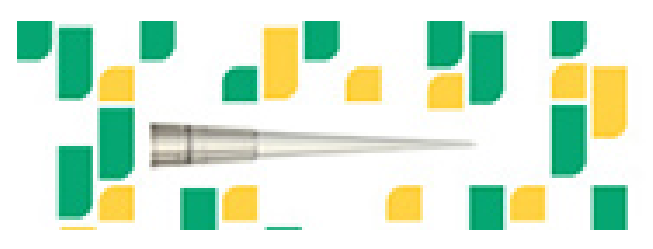

To subscribe to Genome Research go to: https://genome.cshlp.org/subscriptions 